\title{
Pregnant women's knowledge, perception and attitudes towards caesarian section among obstetrics unit attendants in a teaching hospital
}

\author{
Dorkenoo, J.E., *Abor, P.A.
}

\begin{abstract}
Background: This study investigated pregnant women's knowledge level, perception and attitudes towards caesarean section in the Obstetrics Unit at the Korle-Bu Teaching Hospital.
\end{abstract}

Methods: We employed a descriptive cross-sectional survey design to conduct the study.

Results: The findings of the study revealed that majority (82.2\%) of pregnant women have considerable knowledge about conditions that predisposes a woman for caesarean section as well as the risk of complications. Factors which significantly encouraged respondents to undergo caesarean section deliveries were they being necessary to protect the health of their babies (85.8\%), having more knowledge about caesarean section procedures and risks and trusting in the competence of the doctor (53\%). On the other hand, the study identified some inhibiting factors such as $67 \%$ of women perceive that caesarean sections take away the joy of a woman, while giving birth. Respondents $(56 \%)$ however, indicate that caesarean sections were not unnatural nor only reserved for those with medical issues or those who fear pain; they are not embarrassing to reveal to family, friends, etc.

Conclusion: In the case of a tertiary hospital in Ghana, women attending antenatal clinic have acquired adequate knowledge and fairly good attitudes and perceptions about caesarean section, its benefits and possible complications. The findings of this study have important policy and practical implications for other levels hospitals.

Keywords: Pregnant women, caesarean section, vaginal birth, perception, hospital, Ghana

*Corresponding author

Abor, P.A.

ORCID-NO: http://orcid.org/0000-0001-6342-8184

Email:pabor@ug.edu.gh;

Department of Public Administration and Health Services Management University of Ghana Business School, Legon, Ghana. 


\title{
Connaissances, perceptions et attitudes des femmes enceintes à l'égard de la césarienne chez les préposés à l'unité d'obstétrique dans un hôpital universitaire
}

\author{
Dorkenoo, J.E., *Abor, P.A.
}

\begin{abstract}
Resume
Contexte: Cette étude a examiné le niveau de connaissance, la perception et les attitudes des femmes enceintes vis-à-vis de la césarienne dans l'unité d'obstétrique de l'hôpital universitaire de Korle-Bu.
\end{abstract}

Méthodes: Nous avons utilisé un plan d'enquête descriptif transversal pour mener l'étude.

Résultats: Les résultats de l'étude ont révélé que la majorité $(82,2 \%)$ des femmes enceintes ont des connaissances considérables sur les conditions qui prédisposent une femme à une césarienne ainsi que sur le risque de complications. Les facteurs qui ont fortement encouragé les répondantes à subir des accouchements par césarienne étaient-ils nécessaires pour protéger la santé de leurs bébés $(85,8 \%)$, avoir plus de connaissances sur les procédures et les risques de la césarienne et avoir confiance dans la compétence du médecin (53\%). D'autre part, l'étude a identifié certains facteurs inhibiteurs tels que 67\% des femmes perçoivent que les césariennes enlèvent la joie d'une femme, lors de l'accouchement. Les personnes interrogées $(56 \%)$ indiquent cependant que les césariennes n'étaient pas artificielles ni réservées uniquement aux personnes ayant des problèmes médicaux ou à celles qui craignent la douleur ; ils ne sont pas gênants à révéler à la famille, aux amis, etc.

Conclusion: Dans le cas d'un hôpital tertiaire au Ghana, les femmes fréquentant la clinique prénatale ont acquis des connaissances adéquates et des attitudes et perceptions assez bonnes concernant la césarienne, ses avantages et ses complications possibles. Les résultats de cette étude ont des implications politiques et pratiques importantes pour les hôpitaux d'autres niveaux.

Mots clés: Femmes enceintes, césarienne, accouchement vaginal, perception, hôpital, Ghana

*Corresponding author

Abor, P.A.

ORCID-NO: http://orcid.org/0000-0001-6342-8184

Email:pabor@ug.edu.gh;

Department of Public Administration and Health Services Management University of Ghana Business School, Legon, Ghana.

Research Journal of Health Sciences subscribed to terms and conditions of Open Access publication. Articles are distributed under the terms of Creative Commons Licence (CC BY-NC-ND 4.0). (http://creativecommons.org/licences/by-nc-nd/4.0)

http://dx.doi.org/10.4314/rejhs.v9i3.2 


\section{INTRODUCTION}

Caesarean section (CS) is considered by medical professionals to be relatively safe, though, it does in fact pose a higher risk for complications than vaginal delivery (1). The term "caesarean" was derived from a decree in Roman law, which made it mandatory for children to be cut out of women who had died during childbirth. In fact, the term used at the time was 'Lex Caesarae' $(2,1)$. A caesarean section denotes the use of surgery to deliver one or more babies from a mother's womb (3). This type of surgery has been in existence throughout medical history and has steadily progressed from being one that is totally fatal to one that is safe for both the mother and the foetus (1). Contrary to caesarean section, spontaneous vaginal delivery (SVD) is the most commonly accepted and widely used method for child delivery worldwide. It is the process through which childbirth naturally occurs through the birth canal (3).

Caesarean section is now a common surgical operation around the world with many being aware of the existence of this medical procedure (4). The recent rates of delivery by caesarean section continue to rise worldwide, with reported rates of $24.5 \%$ in Western Europe, $32 \%$ in North America, and $41 \%$ in South America (5). Delivery by caesarean section can minimise maternal and perinatal mortality and morbidity when there are maternal or fetal complications (6). However, there are several instances when babies are delivered by caesarean section when there is no medical or obstetric indication $(7,8)$.

The perception of women about birth especially by caesarean section is important for most healthcare providers around the world (3). Considering the perceptions and attitudes towards caesarean section, most pregnant women and their relations view their individual perception and attitudes towards caesarean section delivery as one that is important in the decision-making process. Also, the experience women have at childbirth and their perceptions of that event can affect their feelings of satisfaction, strength, esteem and the value they place on their achievement. For instance, there are many reported cases of women who have considered themselves to be sexually disadvantaged after a vaginal delivery, whiles others who have undergone a caesarean section consider as a disadvantage the distortion in their body image as a result of the surgical incision made (9).

With respect to developing countries (such as Ghana), the perceptions and attitudes towards caesarean section delivery is still a major cause for concern (10). Although there are many who consider caesarean section to be either safe or unsafe, more costly than the normal vaginal delivery and more prone to complications than the SVD, there are some African women who perceive caesarean section to be a sign of female infidelity, a "curse," or a "failure of womanhood" $(11,12)$. In fact, according to Clift-Mathews (13), in developing countries, the negative perception of caesarean section has led to the underutilization of the procedure.

Interestingly, pregnant women's perception of caesarean section has been an essential consideration for providers of healthcare. One of the major reasons is because a positive perception can lead to an effective adaptation to the maternal role whiles a negative perception can leave women with a sense of failure, loss of control, personal disappointment and a cause to distrust their personal abilities as childbearing women, hence the need to promote positive perceptions in caesarean section related issues (14). There are arguments in favour of the use of caesarean section birth to alleviate the pain and complications that arise during normal vaginal births (15). Some studies have also been conducted in an effort to further investigate various related issues about caesarean section delivery.

Prior studies have looked at the issue in developed jurisdictions (see 5, 8, 16 - 19), as well as developing countries (see 12, 14, 20 - 24). Few studies exist on the perception and attitudes of pregnant women on caesarean section in Ghana $(25-28)$. This present study contributes to the literature by investigating pregnant women's knowledge, perception and attitudes towards caesarean section in Ghana. Specifically, the study first ascertains pregnant women's knowledge of caesarean section among obstetric unit attendants in the Korle-Bu Teaching Hospital. Secondly, we investigate the factors that encourage or discourage pregnant women at the Korle-Bu Teaching Hospital from having a caesarean section delivery. Lastly, the study examines pregnant women's perception and attitudes towards caesarean section among obstetric unit attendants in the Korle-Bu Teaching Hospital.

The rest of the paper is structured as follows. Section 2 describes the methodology used in the study. Section 3 presents the results, while section 4 discusses the results of the study. Finally, section 5 concludes the study by providing some implications. 


\section{MATERIALS AND METHODS Study Design}

A descriptive cross-sectional survey design was used to conduct the study on pregnant women's knowledge level, perception and attitudes towards caesarean section in the Obstetrics Unit at the Korle-Bu Teaching Hospital.

\section{Study Site and Population}

This study was conducted at the Korle$\mathrm{Bu}$ Teaching Hospital, a tertiary level facility located in the Accra Metropolitan Area in the Greater Accra region of Ghana. It is a 2,000-bed capacity facility with 17 clinical and diagnostic departments / units. It gained a teaching hospital status in 1962 when the University of Ghana Medical School (UGMS) was established for the purpose of training of medical doctors. The obstetrics unit provides antenatal, childbirth, post-natal, and post-partum services. The Korle$\mathrm{Bu}$ Teaching Hospital is currently the third largest hospital in Africa and the leading national referral centre in Ghana. It has an average daily attendance of 1,500 patients with 250 patient admissions (KBTH, 2017). The target population for the study was all pregnant women who visited this facility. The population of this study comprised of the total number of pregnant women who visit the Obstetrics Unit of the Korle$\mathrm{Bu}$ Teaching Hospital in a month. With that said, the average outpatient department (OPD) attendance in the antenatal clinic is approximately 35 non-repeating patients per day, and a month consisted of about 22 working days. The population size is therefore estimated as $35 \mathrm{x}$ $22=770$ patients per month.

\section{Sample Size and Sampling Technique}

A sample size of 263 respondents was used for this particular study. The Yamane Equation (as shown below) was used for the calculation of the sample size:

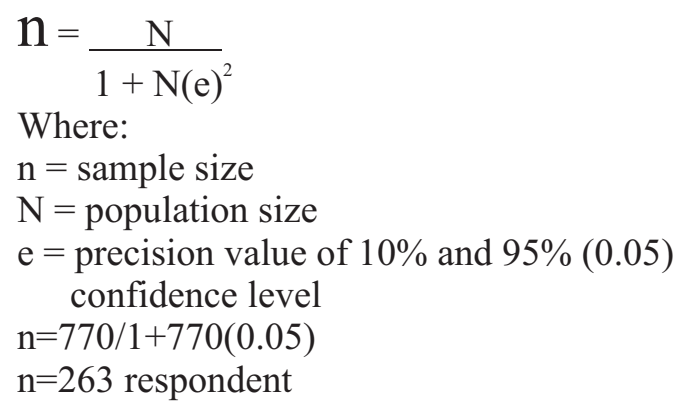

Regarding eligibility criteria, the sample included pregnant women attending antenatal clinic who were available during the study period, were not in labor, were fully conscious, and were of sound mind. Although there are several hospitals in the country providing obstetric care, a purposive sampling technique was used in choosing Korle-Bu Teaching Hospital as the area of study because it is currently the biggest and most specialised referral hospital in the country, thus has people from diverse backgrounds seeking healthcare services there. It also gave the researchers the opportunity to assess the opinions of people from varied backgrounds.

\section{Research Instrument}

A questionnaire was the data collection instrument for this study. The questionnaire was chosen due to the fact that it is easy to administer and allows the researchers to collect large amounts of data from a large sample of a given population at a relatively low cost (29).

\section{Data Collection}

Afterwards, questionnaires were administered to 263 pregnant women at the unit. Out of 263 respondents that were surveyed, 219, representing $83.27 \%$ of properly completed questionnaires were retrieved. The data was collected over a period of 15 non-consecutive days. In situations where a respondent could not read or fully understand a particular question, it was read and explained as best as possible in the language of her choice. The data that was collected included the respondents' demographic information as well as responses to questions that focused on the objectives of the study.

\section{Reliability and Validity of Instruments}

The reliability of the research instrument was determined using a test-retest reliability. This involved administering questionnaires to members of the research population who were not counted as part of the research sample on two separate occasions. The scores were then correlated to determine the reliability. This also helped in effecting the necessary changes and corrections to the research instrument. The validity of the research instrument was also determined by a face validity method. This involved the researchers incorporating questions from similar studies on the same subject matter in the research instrument.

\section{Data Analysis Techniques}

After the data was collected, it was organised before being inputted and analysed using the Statistical Package for Social Sciences, 
Version 22.0. The analysis was done using descriptive statistics.

\section{Ethical Consideration}

During the study, openness and honesty with all of the respondents with respect to the purpose of the study, the methods to be used during the study, the potential outcomes of the study and the related discomforts, demands and inconveniences was explained and ensured. Permission was obtained from the Head of the obstetrics unit and the research coordinator of the unit. Information collected from respondents was treated with confidentiality. There was no compensation for any of the research subjects for their participation since that may have possibly encourage some form of bias when answering the questions. Respondent participation was strictly voluntary, and no form of coercion or inducement was made to try to get them to participate in the study.

\section{RESULTS}

\section{Demographic Data and Obstetric Characteristics}

Table 1 presents the demographic and obstetric characteristics of the respondents. Of the respondents that were surveyed, $39(17.81 \%)$ were between the ages of 18 and 30 years, 151 $(68.95 \%)$ were between the ages of 31 and 45 years, and $28(12.79 \%)$ were between the ages of 46 and 60 years This is expected as most women are serious about child birth by age 31 since the majority of women in Ghana tend to marry between the ages of 25 and 29 (Ghana Statistical Service, 2012). In fact, after the age of 45 , it has been observed that women are not very optimistic about bearing children due to possible health complications such as high blood pressure and gestational diabetes. Only $2(0.91 \%)$ of the respondents possessed no education, whereas 93 $(42.47 \%)$ of the respondents said they possessed at least a Senior High School education. Fortyone, representing $18.72 \%$ possessed only a primary school or basic education, 59 (26.94\%) had completed Junior High School, and 21 $(9.59 \%)$ possessed a tertiary education. The results show that the majority (121) representing $55.25 \%$ of respondents were gainfully employed in some form of employment, whereas the 53 $(24.21 \%)$ of respondents were unemployed. Forty-five $(20.55 \%)$ were informally employed. Regarding the marital statuses of the respondents that were surveyed, more than half (111) representing $50.68 \%$ were married. The rest, 57 $(26.03 \%)$ were cohabitating, while $36(16.44 \%)$ were single. Majority of the respondents being married is expected as the Ghanaian cultural values encourage childbirth in marriage as opposed to bearing children out of wedlock. Regarding the religious beliefs (or faiths) of the respondents that were surveyed, majority (173) accounting for $79 \%$ indicated that they were Christians, 28 (12.79\%) indicated being Muslims, 5 (2.28\%) indicated that they were Traditionalists, and $13(5.94 \%)$ chose Other. Of the 13 who chose Other, 9 were Mormon, 3 were Baha'i, and 1 was Hindu.

When respondents were asked how many caesarean section births they had undergone during their lifetime, 109 (49.77\%) indicated they had never experienced caesarean section birth, 83 (37.90\%) indicated once, 21 $(9.59 \%)$ said twice, and $6(2.74 \%)$ indicated thrice (see Table 1). From these findings, it can be seen that the majority of the respondents were coming to the antenatal clinic to experience a caesarean section for the very first time, and that the second highest number had experienced the operation only once prior to the impending caesarean section. In addition, there were not so many respondents who had experienced a caesarean section twice or thrice.

\section{Knowledge of Pregnant Women on Caesarean Section}

Table 2 presents results on the pregnant women's knowledge on caesarean section. Majority of respondents 216 (98.63\%) considered vaginal deliveries to be safer than caesarean section deliveries for both mothers and babies and were correct in their views. Also, majority of respondents $133(60.73 \%)$ were of the view that mothers can undergo a normal vaginal delivery even after a caesarean section birth and were correct. A little over half of respondents 120 (54.79\%) were correct about the assertion that the healing of the scar of a caesarean section incision depends upon one's genetics. Majority of respondents 180 representing $82.19 \%$ were correct that a woman could opt for a caesarean section by choice. Most respondents 171 $(78.08 \%)$ were correct that it could take about 3 to 7 days for a caesarean section patient without medical complication to be discharged from the hospital.

More than half of respondents 131 $(59.82 \%)$ were correct in their rejection of the assertion that women with certain blood groups are not permitted to undergo caesarean section delivery. $187(85.39 \%)$ respondents were correct in their views that a woman who is weak as a 
result of prolonged labour is allowed to undergo a caesarean section delivery, and an overwhelming number of 198 (90.41\%)women correctly held the opinion that women with medical conditions such as hypertension can have a caesarean section. When respondents were asked if a baby with a malpresentation at birth can be delivered by a caesarean section, 200 accounting for $91.32 \%$ of the respondents were correct with their "Yes" responses, whereas $8.68 \%$ (19) of the respondents were incorrect with their "No" responses. More than $90 \%$ of respondents 211 (96.35\%) were correct in their view that twins and triplets can be delivered by a caesarean section delivery, and also most respondents 177 $(80.82 \%)$ were correct in their view that big babies should be delivered by a caesarean section.

\section{Factors Encouraging or Discouraging Women from Caesarean Section Births}

When respondents were asked if they believed that caesarean section delivery is very risky to both mother and child, 51.1\% (112) indicated "Strongly Agree"; 35.2\% (77) indicated "Agree"; 1.4\% (3) indicated "Not Sure"; 6.8\% (15) indicated "Disagree"; and 5.5\% (12) indicated "Strongly Disagree". The overall interpretation points to "Agree" (see Table 3). In finding out if they were discouraged by the notion that a caesarean section can lead to excessive blood loss, 30.6\% (67) indicated "Strongly Agree"; 39.3\% (86) indicated "Agree"; 0.5\% (1) indicated "Not Sure"; $7.3 \%$ (16) indicated "Disagree"; and 22.4\% (49) indicated "Strongly Disagree" (see Table 3). The overall interpretation points to "Not Sure." Looking at whether the women would not undergo a caesarean section due to the long recovery period, 35.2\% (77) indicated "Strongly Agree"; 49.8\% (109) indicated "Agree"; $14.6 \%$ (32) indicated "Disagree"; and $0.5 \%$ (1) indicated "Strongly Disagree" (see Table 3). The overall interpretation points to "Agree." When respondents were asked if they would not undergo a caesarean section since it causes more complications than vaginal delivery, 65.8\% (144) indicated "Strongly Agree"; 32.0\% (70) indicated "Agree"; 0.9\% (2) indicated "Disagree"; and $1.4 \%$ (3) indicated "Strongly Disagree".

In ascertaining whether respondents would not undergo a caesarean section since they could possibly die on the operating table, 5.5\% (12) indicated "Strongly Agree"; 13.2\% (29) indicated "Agree"; $2.7 \%$ (6) indicated "Not Sure"; 44.7\% (98) indicated "Disagree"; and
33.8\% (74) indicated "Strongly Disagree" (see Table 3). When respondents were asked if they would undergo a caesarean section if it were necessary to protect the health of their baby, $85.8 \%$ (188) indicated "Strongly Agree"; and 14.2\% (31) indicated "Agree" (see Table 3). Looking at respondents if they would undergo a caesarean section if their close friends and family consented to it, 46.1\% (101) indicated "Strongly Agree"; 28.8\% (63) indicated "Agree"; 12.8\% (28) indicated "Disagree"; and 12.3\% (27) indicated "Strongly Disagree".

When respondents were asked if they would undergo a caesarean section to avoid labour pains, $1.8 \%$ (4) indicated "Strongly Agree"; 2.7\% (6) indicated "Agree"; $1.4 \%$ (3) indicated "Not Sure"; 67.6\% (148) indicated "Disagree"; and 26.5\% (58) indicated "Strongly Disagree" (see Table 3). Ascertaining if they would undergo a caesarean section if they were more knowledgeable about the procedure and risks, 49.8\% (109) indicated "Strongly Agree"; 45.2\% (99) indicated "Agree"; 0.9\% (2) indicated "Not Sure"; 3.2\% (7) indicated "Disagree"; and $0.9 \%$ (2) indicated "Strongly Disagree" (see Table 3). Again, when respondents were asked if they would undergo a caesarean section if a doctor that they trusted conducted it, 53.0\% (116) indicated "Strongly Agree"; 26.5\% (58) indicated "Agree"; 13.7\% (30) indicated "Not Sure"; 3.2\% (7) indicated "Disagree"; and 3.7\% (8) indicated "Strongly Disagree" (see Table 3 ).

Gauging from the weighted mean averages in Table 3, it can be seen that the factors which significantly encouraged respondents to undergo caesarean section deliveries were they being necessary to protect the health of their babies $(4.86,0.018)$, respondents having more knowledge about caesarean section procedures and risks $(4.40,0.891)$, and respondents trusting in the performing doctor $(4.22,0.420)$. On the other hand, the significant discouraging factors included caesarean sections being very risky to mother and child (4.20, 0.928), the relatively long recovery period of caesarean section deliveries $(4.05,0.113)$, and caesarean section deliveries causing more complications than vaginal deliveries (4.60, 0.192).

\section{Women's General Perceptions and Attitudes Towards Caesarean Section}

When respondents were asked if they believed that any woman could have a caesarean section by choice, 91.8\% (201) indicated "Strongly Agree"; and 8.2\% (18) indicated 
"Agree" (see Table 4). The overall interpretation points to "Agree." Finding out if they believed that caesarean section births are unnatural and reserved for those with medical issues or those who fear pain, 2.3\% (5) indicated "Agree"; $6.8 \%$ (15) indicated "Not Sure"; $56.2 \%$ (123) indicated "Disagree"; and 34.7\% (76) indicated "Strongly Disagree". The overall interpretation points to "Strongly Disagree." In ascertaining if having a caesarean section takes away from the joy of giving birth, 67.1\% (147) indicated "Strongly Agree"; 26.5\% (58) indicated "Agree"; $5.5 \%$ (12) indicated "Disagree"; and $0.9 \%$ (2) indicated "Strongly Disagree". The overall interpretation points to "Agree." When respondents were asked if they would feel embarrassed to inform close family, friends, etc. that they had given birth by caesarean section, 6.8\% (15) indicated "Strongly Agree"; $23.3 \%$ (51) indicated "Agree"; 4.6\% (10) indicated "Not Sure"; $25.1 \%$ (55) indicated "Disagree"; and $40.2 \%$ (88) indicated "Strongly Disagree". The overall interpretation points to "Disagree."

Looking at whether they believed that having a vaginal birth was a more empowering experience than delivering by caesarean section, 9.6\% (21) indicated "Strongly Agree"; $22.4 \%$ (49) indicated "Agree"; $40.2 \%$ (88) indicated "Not Sure"; $16.9 \%$ (37) indicated "Disagree"; and $11.0 \%$ (24) indicated "Strongly Disagree" (see Table 4). The overall interpretation points to "Not Sure." When respondents were asked if they believed that the experience of child delivery was better with a caesarean section since labour pains are small, 21.9\% (48) indicated "Not Sure"; $22.8 \%$ (50) indicated "Disagree"; and 55.3\% (121) indicated "Strongly Disagree". The overall interpretation points to "Strongly Disagree." When respondents were asked if they believed that a woman recovers faster after a caesarean section than after vaginal birth, $0.9 \%$ (2) indicated "Not Sure"; $20.1 \%$ (44) indicated "Disagree"; and 79.0\% (173) indicated "Strongly Disagree". The overall interpretation points to "Strongly Disagree" (see Table 4).

Regarding the attitudes and perceptions of the pregnant women, they were generally of the view that any woman can have a caesarean section birth by choice $(4.92,0.181)$, and that having a caesarean section takes away from the joy of childbirth $(4.53,0.484)$. They also believe that caesarean section births are not unnatural and not reserved for those with medical issues or those who fear pain $(1.77,0.192)$, that they would not feel embarrassed about informing close family, friends, and others that they had given birth by caesarean section $(2.32,0.817)$, that the experience of child delivery is not better with a caesarean section birth $(1.67,0.245)$, and that a woman does not recover faster after a caesarean section than after a vaginal birth $(1.22,0.891)$.

\section{DISCUSSION}

The first objective of this study was to ascertain the knowledge pregnant women at the Korle-Bu Teaching Hospital had about caesarean section deliveries. The findings of the study showed that majority (between 55\% and 99\%) of the pregnant women had adequate knowledge and were aware of all of the factors concerning caesarean section deliveries that were asked of them during the survey. This finding is in line with that of Lauwers and Swisher (18), who found that compared to the developed world, many of those residing in developing countries also have considerable knowledge about the pros and cons of caesarean section births. In terms of comparison to other studies, these findings were better than Mungrue et al.'s (20) Trinidadian study, which found that majority $(46.2 \%)$ of the women who were surveyed possessed very little information from which to make informed decisions about selecting caesarean sections as their preferred choice of delivery. The Ghanaian situation is also better than what Ajeet et al (22) found in an Indian study. They found that the majority of women $(65.1 \%)$ possessed very little knowledge about caesarean section delivery, although they were aware that such a type of delivery did exist.

Looking specifically at African studies, the Nigerian study by Ashimi et al (24) contrast with the findings of our study as it was found that only $40.9 \%$ of the respondents had adequate knowledge about caesarean section deliveries in Nigeria. The findings of this current Ghanaian study, show remarkable improvement in the knowledge of Ghanaian women regarding caesarean section, compared to the findings of previous studies in Ghana (see 25, 27). Adageba et al (25) for instance found that $13.5 \%$ of the respondents possessed adequate knowledge about caesarean section deliveries, while Prah et al (27) found that $39.6 \%$ of the women surveyed had adequate knowledge about caesarean section.

The second objective was to investigate the factors that encourage or discourage pregnant women at the Korle-Bu Teaching Hospital from having a caesarean section delivery. With respect to the factors the encourage pregnant women's to opt for caesarean section, the finding show that 
respondents would be encouraged to undergo a caesarean section if it was necessary to protect the health of their babies, they were more knowledgeable about the procedures and risks, and / or it was conducted by doctors that they trusted. The need to protect the health of babies is supported by of Lauwers and Swisher (18) that caesarean section deliveries often serve as a medium for saving lives when vaginal delivery seems to be medically life threating to both a mother and fetus. Our finding on having adequate knowledge encouraging caesarean section is also in line with that of Sunday-Adeoye and Kalu (23), who found that the lack of adequate knowledge about caesarean section risks discouraged some of the respondents. On the issue of the caesarean section being performed by a trusted doctor, our finding is in tandem with that in Mungrue et al. (20), who found that majority $(84.4 \%)$ of women in Trinidad surveyed were unwilling to undergo a caesarean section by doctors they did not trust.

On the other hand, respondents seemed to be discouraged by the fact that caesarean section deliveries are very risky to both a mother and child, there is a long recovery period, and it often causes more complications than vaginal delivery. Gabbe et al (15) also found that women consider caesarean section deliveries as risk to both a mother and child serving, as a discouraging factor. Moreover, long recovery period serving as a discouraging factor, is supported by the finding of Sunday-Adeoye and Kalu (23). Also, caesarean section deliveries cause more complications as a discouraging factor for women is in line with the position of Hall (1).

The third objective also examined the general perceptions and attitudes of pregnant women at the Korle-Bu Teaching Hospital towards caesarean section. The findings of the study revealed that majority of the women were of the view that any woman can have a caesarean section by choice, and having a caesarean section takes away from the joy of giving birth. Moreover, that they were of the view that caesarean section births are not unnatural and not reserved for those with medical issues or those who fear pain, it would not be embarrassing to inform close family, friends, etc. that they had given birth by caesarean section, that the experience of child delivery is not better with a caesarean section since labour pains are small, and a woman recovers faster after a caesarean section than after vaginal birth. Concerning any woman being able to have a caesarean section by choice, this was also the view of the majority of the respondents in Roux's (21) South African study. The finding on caesarean section taking away from the joy of giving birth, however, contradicts that of Ajeet et al (22), who found that only $21.5 \%$ of the respondents were of the view that having a caesarean section takes away from the joy of giving birth. Also, in contrast to the findings of this study, Tatar et al (17) found that many of the respondents in their study felt that caesarean section births were unnatural and reserved for those with medical issues. Mboho (12), in a Nigerian study, also found that some women who had undergone caesarean section had been banished from their communities.

\section{CONCLUSION}

Within the context of a tertiary hospital, most women have been found to have acquired adequate knowledge on the conditions that predisposes a woman to having a caesarean section, as well as the benefits, risk, and possible complications of undergoing a caesarean section. This implies that the pregnant women attending antenatal clinic at teaching hospitals are well equipped with the necessary knowledge to make the right decisions with regards to their obstetric health. This study also outlined responses from pregnant on the factors that will make them choose a caesarean section or otherwise. These factors if taken into consideration could help reduce, if not eliminate the maternal mortality rates caused by women's refusal of caesarean sections during complicated/contracted labor. Finally, the findings of the study revealed that these pregnant women were not generally concerned about the societal myths and thus would not be embarrassed informing close relations and friends about going through with a caesarean section. This current study shows a clear improvement on the level of knowledge, perception and attitude of pregnant women on the subject of caesarean section, from similar previous studies in Ghana, Nigeria and South Africa.

In view of the findings of this study, it is recommended that the Ministry of Health through its partnering agents and departments need to put in place an initiative to educate more women in other hospitals, especially those at the secondary and primary levels, about caesarean section deliveries. This will able to reap the potential benefits in terms of preventing untimely deaths and health complications. Hospitals in the country should focus more on enlightening pregnant women on the need for caesarean 
sections and assure these women of safe and healthy deliveries through this method, during antenatal sessions. This is considering the fact that some of the women, though few, still lacked adequate knowledge about caesarean section deliveries.

Limitation and Direction of Future Research: This study focused only on one hospital in Ghana and utilized a sample size of only 263 respondents. A qualitative approach could be used with lesser number of respondents to delve deeper into the explanations of the perceptions and attitudes of women towards caesareans section.

\section{Abbreviations \\ CS-Caesarean section \\ KBTH - Korle-Bu Teaching Hospital \\ OPD - Outpatient Department \\ UGMS - University of Ghana Medical School}

Competing interests: The authors declare that they have no competing interests.

Funding: There was no funding for this research.

Authors' contributions: JED was responsible for the data collection, analysis and also discussed aspects of the findings. PAA conceptualised the paper and provided general structure for the paper. She also discussed aspects of the findings and edited the paper.

Acknowledgements: The authors are grateful to the anonymous reviewers for the useful comments.

\section{REFERENCES}

1. Hall, J.E. Guyton and Hall Textbook of Medical Physiology, $13^{\text {th }}$ edition. Philadelphia: Saunders Publishing, 2015.

2. Kwawukume, E.Y. Caesarean section. In: Kwawukume EY, Emuveyan EE, editors. Comprehensive Obstetrics in the Tropics. Dansoman: Asante and Hittscher Printing Press; 2002.p. 321-329

3. Hinkle, J.L. and Cheever, K.H. Brunner \& Suddarth's Textbook of Medical-surgical Nursing, $14^{\text {th }}$ edition. New York, NY: Lippincott, Williams and Wilkins Publishing, 2016.

4. Webb, A., Angus, D. \& Finfer, S. Oxford Textbook of Critical Care, $2^{\text {nd }}$ edition. Oxford, UK: Oxford University Press, 2016.

5. Betran AP, Ye J, Moller AB, Zhang J, Gulmezoglu AM, Torloni MR. The Increasing Trend in caesarean section rates: Global, regional and national estimates: 1990-2014. PLoS ONE. 2016;11(2):e0148343. pmid:26849801

6. Gibbons L, Belizan JM, Lauer JA, Betra AP, Merialdi M, Althabe F. The Global Numbers and Costs of Additionally Needed and Unnecessary Caesarean Sections Performed per Year: Overuse as a Barrier to Universal Coverage. Background Paper, 30, World Health Report, 2010.

7. Thomas J, and Paranjothy S. Royal College of Obstetricians and Gynaecologists Clinical Effectiveness Support Unit. National Sentinel Caesarean Section Audit Report. RCOG Press; 2001.

8. Keag OE, Norman JE, Stock SJ. Long-term risks and benefits associated with cesarean delivery for mother, baby, and subsequent pregnancies: Systematic review and meta-analysis. PLoS Med, $2018 ; 15(1)$ : e 1002494 . https://doi.org/10.1371/journal.pmed.1002494

9. McAra-Couper, J., Jones, M. \& Smythe, E. Rising rates of intervention in childbirth.British Journal of Midwifery, 2010; 18(3), 160-169

10. Eifediyi RA, Isaba $P, A$ khimiona $\mathrm{V}$, Affusim CC, Ikheloa J, Njoku A. Caesarean Section: awareness, perception and accessibility of Caesarean Section among subrural Nigerian patients. Int $\mathbf{J}$ of Gynaecogical and Obstetrical Research. 2015;3(1): 7-12.

11. Adeoye-Sunday, I., \& Kalu, C.A. Pregnant Nigerian women's view of caesarean section. Niger J ClinPract. 2011; 14: 276-9.

12. Mboho, M. Perception of Nigerian women towards caesarean section: A case study of women of reproductive age in Akwa Lbom State, Nigeria. Academic Research International, 2013; 4(6), 272-280.

13. Clift-Mathews, V. Vaginal Birth as a Rite of Passage, British Journal of Midwifery, 2020; 18(3), $15-17$

14. Mboho, M., Furber, C. and Waterman, H. Socialcultural Practices and Beliefs Influencing Maternal mortality, African Journal of Midwifery and Women's Health, 2013;

7(1), https://doi.org/10.12968/ajmw.2013.7.1.26

15. Gabbe, S.G., Niebyl, J.R., Simpson, J.L., Landon, M.B., Galan, H.L., Jauniaux, E.R.M., Driscoll, D.A., Berghella, V. and Grobman, W.A. Ostetrics: Normal and problem pregnancies, $7^{\text {th }}$ edition. New York, NY: Elsevier Publishing, 2016.

16. Blamer, K. A Comparative Study of Women's Perceptions of Vaginal and caesarean births (master's thesis). Grand Valley State University, Allendale, Michigan, 1999.

17. 'Tatar, M., Guinalp, S., Somunoglu, S. \& Demirol, A. Women's perceptions of caesarean section: Reflections from a Turkish teaching hospital. Social Science \& Medicine, 2000; 50(9), 12271233

18. Lauwers, J. \& Swisher, A. Counselling the nursing mother: A lactation consultant's Guide. New York, NY: Jones \& Bartlett Publishers, 2010. 
19. Zhao, Y., Zhang, J., Hukkelhoven, C., Offerhaus, P, Zwart, J., de Jonge, A. and Geerts, C. (2016), Modest Rise in Caesarean Section from 2000-2010: The Dutch Experience, PLoS One, 2016; 11(5), doi: 10.1371/journal.pone.0155565

20. Mungrue, K., Nixon, C., David, Y., Dookwah, D., Durga, S., Greene, K. \& Mohammed, H. (2010). Trinidadian women's knowledge, perceptions and preferences regarding caesarean section: How do they make choice? International Journal of Women's Health, 2010(2), 387-391.

21. Roux, S.. An exploratory study of mothers' perceptions and experiences of an unplanned caesarean section (Master's thesis). North-West University, Potchefstroom, South Africa, 2010.

22. Ajeet, S., Jaydeep, N., Nandkishore, K. \& Nisha, R. Women's knowledge, perceptions, and potential demand towards caesarean section. National Journal of Community Medicine, 2011; 2(2), 244-248.

23. Sunday-Adeoye, I. \& Kalu, CA. Pregnant Nigerian women's view of cesarean section. Nigerian Journal of Clinical Practice, 2011; 14(3), 276-279.

24. Ashimi, A.O., Amole, T.G. \& Aliyu, L.D Knowledge and attitude of pregnant Women to caesarean section in a semi-urban community in northwest Nigeria. Journal of the West African College of Surgeons, 2013; 3(2), 46-61.

25. Adageba, R.K., Danso, K.A., Adusu-Donkor, A. \& Ankobea-Kokroe, F. Awareness and perceptions of and attitudes towards caesarean delivery among antenatal. Ghana Medical Journal, 2008; 42(4), 137-140.

26. Danso, K., Schwandt, H.M., Seffah, J.D. \& Hindin, M.J. Preference of Ghanaian Women for vaginal or Caesarean delivery postpartum. Ghana Medical Journal, 2009; 43(1), 29-33.

27. Prah, J. K., Kudom, A., Lasim, O. U. and Abu, E. K. Knowledge, Attitude and Perceptions of Pregnant Women towards Caesarean Section among Antenatal Clinic attendants in Cape Coast, Ghana, Texila International Journal of Public $\mathrm{H}$ e a $1 \mathrm{th}, \quad 2017$; 5 ( 1 ), D O I : 10.21522/TIJPH.2013.05.01.Art007

28. Afaya, R. A., Bam, V., Apiribu, F., Agana, V. A. and Afaya, A. Knowledge of Pregnant Women on Caesarean Section and their Preferred Mode of Delivery in Northern Ghana, NUMID HORIZON: An International Journal of Nursing and Midwifery, 2018;2(1), 62-73

29. Ponto, J., Understanding and Evaluating Survey Research. Journal of the Advanced Practitioner in Oncology. 2015 Mar-Apr; 6(2):168-171

How to cite this article:

Dorkenoo, J.E., Abor, P.A. Pregnant women's knowledge, perception and attitudes towards caesarian section among obstetrics unit attendants in a teaching hospital. Research Journal of Health Sciences, 2021, 9(3): 207-220 
Table 1: Demographic Data and Obstetric Characteristics

\begin{tabular}{|c|c|}
\hline Characteristics & $\mathbf{N}(\%)$ \\
\hline \multicolumn{2}{|l|}{ Age Group } \\
\hline $18-30$ & $39(17.81)$ \\
\hline $31-45$ & $151(68.95)$ \\
\hline $46-60$ & $28(12.79)$ \\
\hline \multicolumn{2}{|l|}{ Education } \\
\hline None & $2(0.91)$ \\
\hline Primary & $41(18.72)$ \\
\hline Junior High School & $59(26.94)$ \\
\hline Senior High School & $93(42.47)$ \\
\hline Tertiary & $21(9.59)$ \\
\hline \multicolumn{2}{|l|}{ Employment Status } \\
\hline Unemployed & $53(24.21)$ \\
\hline Informal Employment & $45(20.55)$ \\
\hline Formal Employment & $121(55.25)$ \\
\hline \multicolumn{2}{|l|}{ Marital Status } \\
\hline Single & $36(16.44)$ \\
\hline Married & $111(50.68)$ \\
\hline Cohabitation & $57(26.03)$ \\
\hline \multicolumn{2}{|l|}{ Religion } \\
\hline Christian & $173(79 \%)$ \\
\hline Muslim & $28(12.79)$ \\
\hline Traditionalist & $5(2.28)$ \\
\hline Other & $13(5.94)$ \\
\hline Mormons & $9(69.23)$ \\
\hline Baha'i & $3(23.07 \%)$ \\
\hline Hindus & $1(7.7 \%)$ \\
\hline \multicolumn{2}{|c|}{ Number of Caesarian Section } \\
\hline 0 & $109(49.77)$ \\
\hline 1 & $83(37.9)$ \\
\hline 2 & $21(9.59)$ \\
\hline 3 & $6(2.74)$ \\
\hline
\end{tabular}


Table 2: Knowledge of Pregnant Women on Caesarean Section

\begin{tabular}{ll}
\hline Response & N (\%) \\
\hline Safer Method of Delivery & $216(98.63)$ \\
Yes & $3(1.37)$ \\
No & \\
Vaginal Delivery after Caesarean Section & $133(60.73)$ \\
Yes & $82(37.44 \%)$ \\
No & \\
Healing of Scar Depends upon Genetics & $120(54.79 \%)$ \\
Yes & $99(45.21 \%)$ \\
No & \\
Opting for a Caesarean Section by Choice & $180(82.19 \%)$ \\
Yes & $37(16.89 \%)$ \\
No & \\
Takes 3 to 7 Day Discharge & $171(78.08 \%)$ \\
Yes & $48(21.92 \%)$ \\
No & \\
Certain Blood Groups and Caesarean Section & $87(39.73 \%)$ \\
Yes & $131(59.82 \%)$ \\
No & \\
Prolonged Labour and Caesarean Section & $187(85.39 \%)$ \\
Yes & $32(14.61 \%)$ \\
Me & \\
Yes & $198(90.41 \%)$ \\
No & $21(9.59 \%)$ \\
Yes & $200(91.32 \%)$ \\
No & $19(8.68 \%)$ \\
Yes & \\
No & $211(96.35 \%)$ \\
Yes & $5(2.28 \%)$ \\
No & $177(80.82 \%)$ \\
Soultiple Babies and Caesarean Section & $41(18.72 \%)$ \\
\hline
\end{tabular}

Source: Field Data 


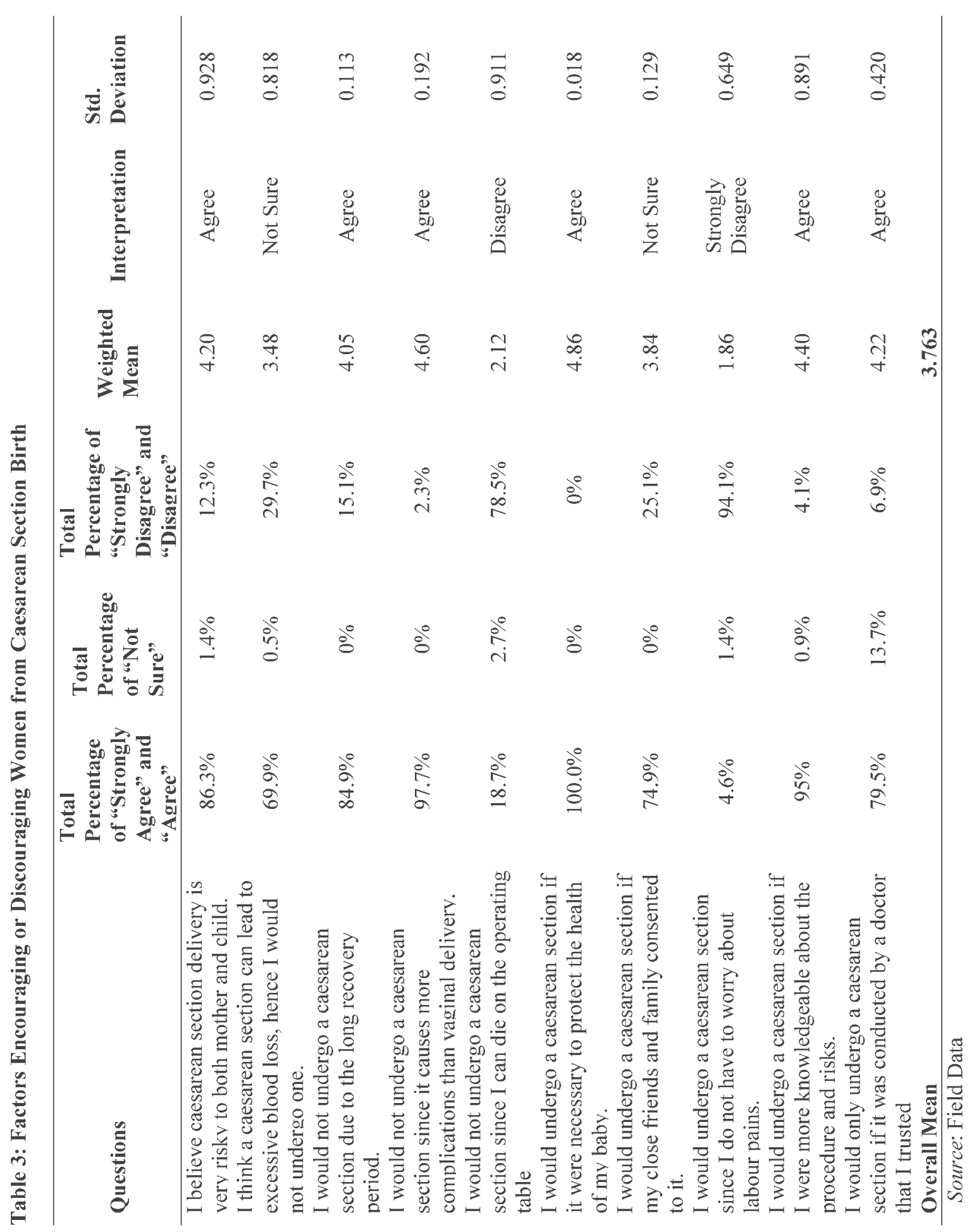




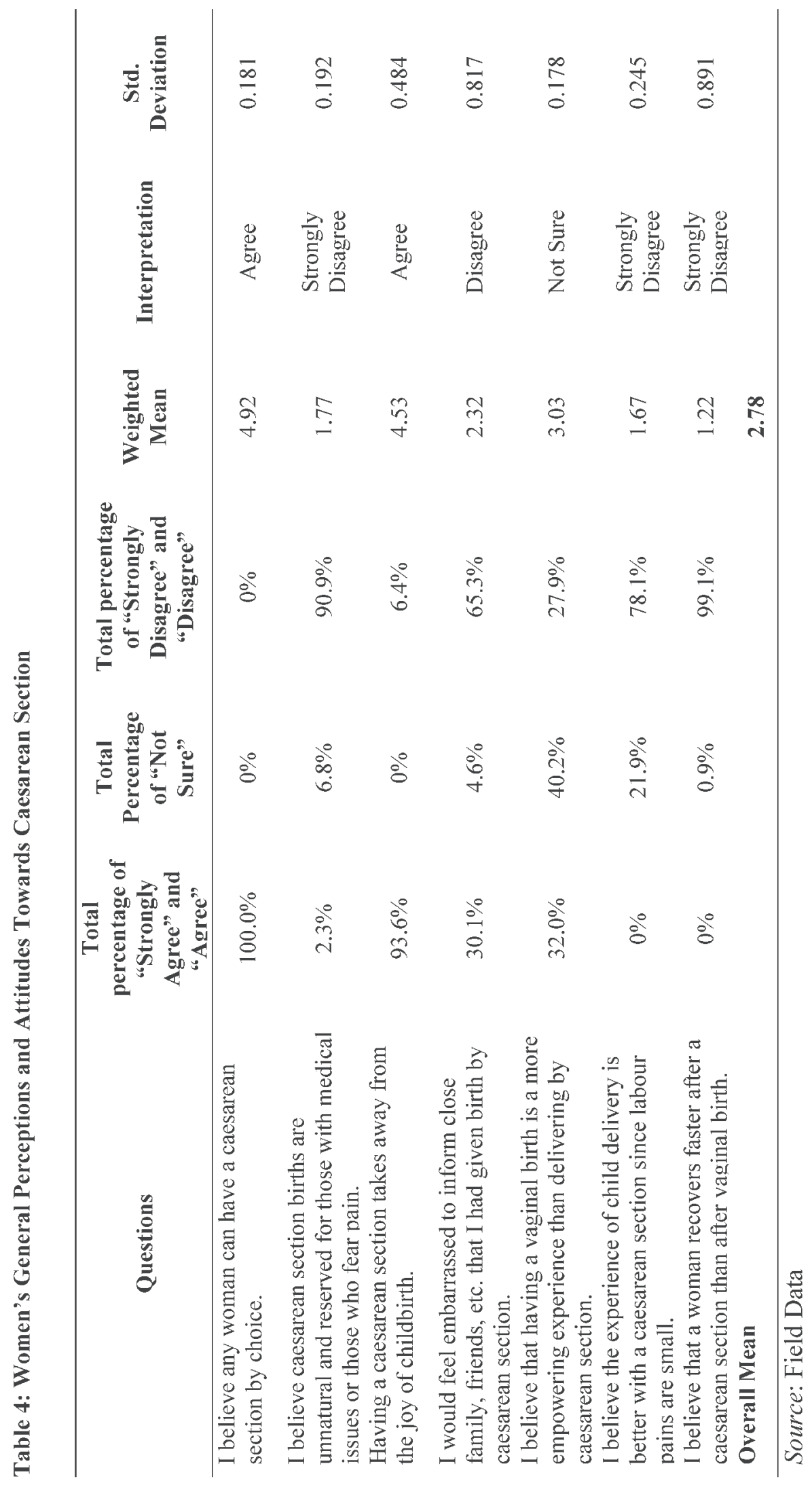

